\title{
Three new species of the genus Philopteroides Mey, 2004 (Phthiraptera, Ischnocera, Philopteridae) from New Zealand
}

\author{
Michel P. Valim ${ }^{1, \dagger}$, Ricardo L. Palma $a^{2, \ddagger}$ \\ I Museu de Zoologia da USP, Av. Nazaré, 481, Ipiranga, São Paulo, SP 04263-000, Brazil 2 Museum of New \\ Zealand Te Papa Tongarewa, P.O. Box 467, Wellington, New Zealand \\ † urn:lsid:zoobank.org:author:4DEAE2A6-0410-45F0-8DD2-02A07C2A3A53 \\ $\ddagger$ urn:lsid:zoobank.org:author:4623C92D-1E7D-47B2-BB4D-CC6B2D39F75B \\ Corresponding author: Michel P. Valim (mpvalim@hotmail.com)
}

Academic editor: V. Smith | Received 13 March 2013 | Accepted 29 April 2013 | Published 10 May 2013

urn:lsid:zoobank.org:pub:CFC6A882-C475-4272-9D6E-7E8FD0283B7C

Citation: Valim MP, Palma RL (2013) Three new species of the genus Philopteroides Mey, 2004 (Phthiraptera, Ischnocera, Philopteridae) from New Zealand. ZooKeys 297: 71-89. doi: 10.3897/zookeys.297.5118

\begin{abstract}
We describe and illustrate three new species of chewing lice in the genus Philopteroides parasitic on passerines (Order Passeriformes, families Acanthizidae, Rhipiduridae and Petroicidae) from New Zealand. They are: Philopteroides pilgrimi sp. n. from Gerygone igata igata; Ph. fuliginosus sp. n. from Rhipidura fuliginosa placabilis and R.f. fuliginosa; and Ph. macrocephalus sp. n. from Petroica macrocephala macrocephala and P. m. dannefaerdi. The identity of Docophorus lineatus Giebel, 1874 is discussed based on its morphology and host association. We also transfer Tyranniphilopterus beckeri to the genus Philopteroides, and provide a key to identify adults of 12 of the 13 species now included in Philopteroides.
\end{abstract}

\section{Keywords}

Philopteroides, Philopteridae, Phthiraptera, lice, new species, new combination, key to species, Passeriformes, New Zealand 


\section{Introduction}

The genus Philopteroides was erected by Mey (2004) to include seven species, three of which he described as new and four of which he transferred from other genera. Najer and Sychra (2012a, b) described two additional species, and we herewith describe three further new species from New Zealand, as well as transfer a species described in the genus Tyranniphilopterus by Mey (2004) to Philopteroides, bringing the total number of species to 13. We also give additional diagnostic characters to distinguish Philopteroides from closely related genera included in the Philopterus-complex (sensu Mey 2004).

Species of the Philopterus-complex are relatively sedentary lice belonging to the docophorid ecotype (Mey 2004) and highly adapted to live on feathers of the host's head $\&$ neck, on which they spend their entire life cycle. The hosts of the 13 species of Philopteroides belong to several families within the avian order Passeriformes, covering a wide geographical distribution over Africa, Asia and Oceania (see below).

\section{Methods}

Specimens examined from New Zealand hosts belong to the Museum of New Zealand Te Papa Tongarewa, Wellington, N.Z. (MONZ), except for some paratypes deposited in the Museu de Zoologia da Universidade de São Paulo, São Paulo, Brazil (MZUSP). The remaining material examined is held in the Naturhistorischen Museum, Rudolstadt, Thüringen, Germany (NHMR). The lice were treated and mounted on slides following the Canada balsam technique (Palma 1978).

All measurements are in millimeters, taken from digitalized images from slidemounted specimens using the software Leica Application Suite (LAS), and identified by the following abbreviations: as3, length of the anterior setae 3; ADPL, anterior dorsal plate length (taken at middle line); ADPLL, anterior dorsal plate lateral length (taken from the base of anterior dorsal setae - ads, to lateral apices of the plate); ADPW, anterior dorsal plate width (taken at its widest point); ANW, width of anterior notch (taken between the bases of as3); AW, maximum width of the abdomen (taken at level of segment V); EWG, external width of genital chamber; GL, male genitalia length; GW, male genitalia width (taken at the basal plate); HL, head length (excluding hyaline membrane); IWG, internal width of genital chamber; POL, preantennal length (taken from the base of the conus to the bases of as3, obliquely to the head axis); POW, preantennal width (taken between bases of the coni); PTW, pterothorax width; PTL, pterothorax length; PW, prothorax width; TL, total length; TPVL, tergal plate V length; TRL, trabecula length; TRW, trabecula width; TW, temporal width.

The sternal abdominal setae are given in sequence from the left to the right side and named by the letters: "L" meaning long and flexible, and "S" meaning short and spine-like. Thus, the first letter indicates the outermost seta on the left side and the last letter the outermost on the right side. For example: LSLS-SLSL if the pattern is symmetrical, or LSLS-L-SLSL if asymmetrical. 
The minute spine-like and the long trichoid setae present on each side of the pterothorax are not included in the number of pterothoracic setae. The chaetotaxy of the abdominal tergocentral setae does not include the postspiracular setae, except for tergite II where postspiracular setae, if present, can not be distinguished from the remaining setae. We regard as pleural setae those situated on the lateral sides of the tergo-pleurites, and as sternal setae those next to the sternites. Some species have ventral setae between the innermost pleural and the outermost sternal setae, which we regard as additional setae.

The nomenclature of head features and setae follows Clay (1951), as amended by Mey (1994). Scientific nomenclature, vernacular names, and the classification of hosts follow those in Dickinson (2003).

\section{Taxonomic treatment}

\section{Philopteroides Mey, 2004}

http://species-id.net/wiki/Philopteroides

Type species. Philopteroides novaezelandiae Mey, 2004 (by original designation).

\section{Two species-groups:}

beckeri species-group: two species

mitsusui species-group: ten species

Host distribution. Passeriformes, suborder Acanthisitti (Acanthisittidae), and suborder Passeri (Acanthizidae, Meliphagidae, Monarchidae Nectariniidae, Petroicidae, Platysteiridae, Pycnonotidae, Rhipiduridae).

Geographical range. Africa (Senegal, Uganda), Asia (India, Vietnam, Taiwan), Oceania (Micronesia, New Zealand).

In addition to those characters mentioned by Mey (2004) in his original description of the genus, we add further diagnostic characters to support the generic position of Philopteroides within the Philopterus-complex.

Diagnosis. Member of the Philopterus-complex by presence of well-developed trabeculae. Anterior dorsal head plate with posterior median projection well developed and sclerotized, but without antero-lateral projections. Hyaline membrane and anterior head plates deeply concave forming an "osculum" (mitsusui group) (Figs 11-12, 34, 36); some species with wide frons (beckeri group) (Figs 9-10). Hyaline membrane deeply or slightly concave, arising from the level of the tips of the marginal carinae or above the anterior setae 3 (as3), with a conspicuous median sclerotization and without additional setae. Marginal carina not interrupted laterally, but with a conspicuous lateral suture on the dorsal surface, at the level of the posterior dorsal sub-medial setae (d.sm.s.). Conus ranging from much reduced to well developed. Marginal temporal setae 2 (m.t.s.2) and pre-ocular setae (p.o.s.) median to short. Prothoracic dorsal setae close to the middle of the segment, and to its posterior margin. Pleuro-tergal plates II-IV without postero-lateral projections ('posterior heads'), but few species with at 
most a slightly pronounced angle on segment II, but not on III or IV. Spine-like setae present on some of the sternites II-VI.

Note. Docophorus lineatus Giebel, 1874 was included in Philopteroides by Mey (2004: 174), when he described it as a new genus. Considering that Giebel's types of this species were lost during the Second World War, and that we have not been able to examine any material from the type host, we follow Mey (2004) in including D. lineatus in Philopteroides, but we are unable to place it in any of the two species-groups which we define below. A neotype for $D$. lineatus is urgently needed to clearly define this species.

\section{Philopteroides lineatus (Giebel, 1874)}

http://species-id.net/wiki/Philopteroides_lineatus

Docophorus lineatus Giebel, 1874: 91.

Philopterus lineatus (Giebel, 1874); Harrison 1916: 98; Hopkins and Clay 1952: 285;

Price et al. 2003: 215.

Philopteroides lineatus (Giebel, 1874); Mey 2004: 174.

Type host. Arachnothera longirostra (Latham, 1790) - Little spiderhunter (Nectariniidae). See note below.

Distribution. Unknown. The original description does not include a type locality. There are 13 subspecies of $A$. longirostra distributed throughout the Indo-Malayan region (Dickinson, 2003).

Remarks. Considering current louse species descriptions, Giebel's (1874) description of Docophorus lineatus is superficial and without any illustration. However, from Giebel's original comparison of this species with Docophorus communis (= Philopterus citrinellae (Schrank, 1776)), and in agreement with Harrison (1916), Hopkins and Clay (1952) and Price et al. (2003), we believe, without doubt, that $D$. lineatus belongs to the Philopterus-complex.

In his original description, Giebel (1874) clearly states “... Schläfenecke drei sehr lange über den Prothorax hinausragende" (= "... marginal temporal carina with three very long macrochaetae projecting beyond the prothorax"). This feature is present in species of Philopterus Nitzsch, 1818 sensu stricto, Clayiella Eichler, 1940, and in a few species of Mayriphilopterus Mey, 2004, but not in species of Philopteroides which have, at most, two long marginal temporal setae $(m t s)$, with the $m t s 2$ always short (Mey 2004). Hence, it would appear that D. lineatus is not a Philopteroides sensu stricto, unless Giebel (1874) included the ocular seta - which is medium to long in Philopteroides - in his three long marginal temporal setae, but the ocular seta does not project beyond the pronotum. Therefore, until material from the type host becomes available to allow for a neotype designation, it is not possible to establish with certainty the correct generic position of $D$. lineatus within the Philopterus-complex.

Regarding the host-louse association of Docophorus lineatus, Giebel (1874) gave the type host as "Arachnothera (Certhia) longirostris". Hopkins and Clay (1952: 285) 
interpreted that host species as being conspecific with "Certhia b. brachydactyla Brehm", according to the bird nomenclature of the time. However, Dickinson (2003: 714) listed Arachnothera longirostra (Latham, 1790) as a valid species in the family Nectariniidae, as well as Certhia brachydactyla Brehm, 1820 as a valid species in the family Certhiidae (Dickinson 2003: 648). In our opinion, the name of the species of the type host given by Giebel (1874) is the most important piece of information to establish the correct type host, regardless of the genus or subgenus associated with that species. Therefore, in agreement with Mey (2004: 174, footnote), we consider that the type host of D. lineatus is Arachnothera longirostra (Latham, 1790). The fact that another species of Philopteroides has a type host in the family Nectariniidae (see Philopterus sclerotifrons Tandan, 1955 below) is further evidence that (1) Arachnothera longirostra is the correct type host for D. lineatus and (2) Philopteroides may be the correct genus for D. lineatus. Furthermore, there is no species of Philopteroides recorded from any member of the Certhiidae.

\section{beckeri species-group}

The trapezoidal shape of the head is a distinctive character in the two species of this group. The preantennal region is short (POL 0.15-0.18) and broad (ANW 0.130.15 ), with a hyaline margin shallowly concave at midline. Conus very reduced.

\section{Philopteroides beckeri (Mey, 2004) comb. n.}

http://species-id.net/wiki/Philopteroides_beckeri

Figs 1-2, 9, 13-16, 29-31

Tyranniphilopterus beckeri Mey 2004: 182; Cicchino 2007: 49.

Type host. Platysteira cyanea nyansae Neumann, 1905 - Brown-throated wattle-eye. (Platysteiridae)

\section{Distribution. Uganda.}

This species was recently described in detail and, therefore, it is not necessary to redescribed it again. We only include habitus images of the holotype male and one paratype female (Figs 1-2), not figured in the original description by Mey (2004). We also include illustrations to support our change of the original generic combination of this species, and have re-drawn only those characters (Figs 9, 13-16, 30) useful to distinguish it from the second species described below. In addition, the second nymphal stage is described from a single specimen (Fig. 29) mounted together with the female paratype, and a re-interpretation of the male genitalia is presented in Fig. 31.

All species of the genus Tyranniphilopterus Mey, 2004 have the following characters, which are lacking in "Tyranniphilopterus" beckeri: (1) hyaline margin arises at a level below the as3; (2) conspicuous antero-lateral projections on anterior dorsal head plate; (3) prothoracic dorsal setae located on the posterior-lateral angles of the seg- 


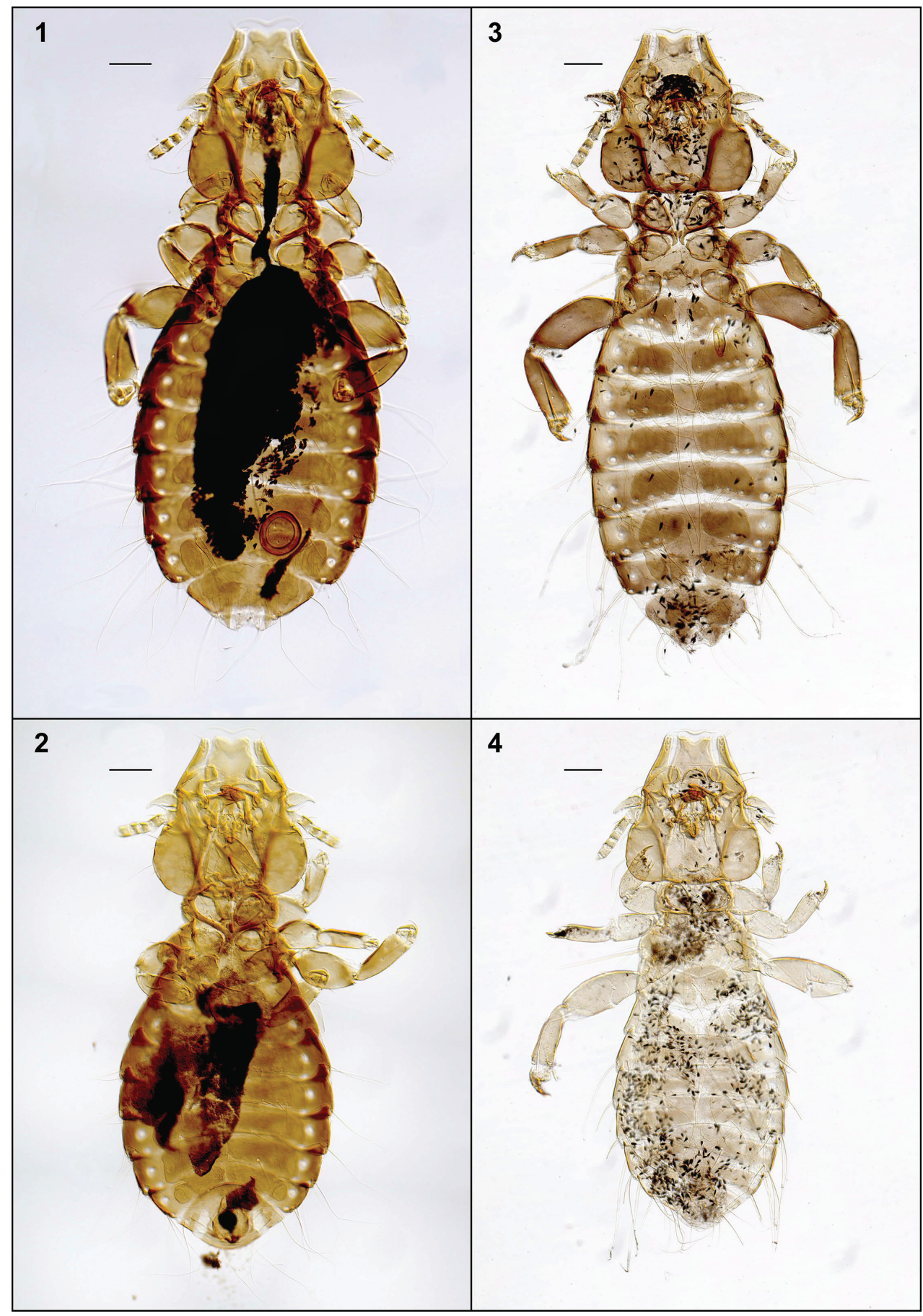

Figures I-4. Habitus, ventral views: Philopteroides beckeri female paratype (I); Ph. beckeri male holotype (2); Ph. pilgrimi female holotype (3); Ph. pilgrimi male paratype (4). Scale bars $=0.1 \mathrm{~mm}$ 
ment, not on its posterior margin.; (4) pleuro-tergal plates II-III with well developed postero-lateral projections. Instead, "Tyranniphilopterus" beckeri has the features which define Philopteroides. These morphological features justify placing it in the latter genus, as Philopteroides beckeri (Mey, 2004) new combination.

Furthermore, the hosts of all species of Tyranniphilopterus - except for "Tyranniphilopterus" beckeri - belong to the passerine suborders Tyranni and Passeri, and are confined to the Americas, while the hosts of all species of Philopteroides belong to the passerine suborders Passeri and Acanthisitti distributed in Africa, Asia and Oceania. Hence, the geographical distribution of its host is further evidence that placing "Tyranniphilopterus" beckeri in the genus Philopteroides is correct.

Description of second nymphal stage. Head, thorax and abdomen as in Fig. 29. Head sub-conical, marginal carina entire laterally, with well developed anterior dorsal and ventral head plates. Anterior setae 3 (as3) rigid, 0.04 in length. Dorsal head plate with convex lateral margins and almost straight posterior margin, bearing rigid anterior dorsal head setae $(a d s)$, as the adults. Anterior ventral plate cordiform. Marginal temporal setae 3 (m.t.s.3) very long, other temporal setae short to minute. Each of the pair of posterior setae on pronotum located half way between the middle of the segment and its lateroposterior angle. Only four long pterothoracic setae, as in the second nymphal stage of most species of Philopteridae (Mey 1994). Abdomen mostly membranous, except for the tergo-pleural plate of second segment (first visible), and the pleural plates of segments III-V. Segments VI and VII with small patches of light sclerotization. Abdominal chaetotaxy as in Fig. 29, with two long dorsal setae plus the postspiracular seta on each side of segments III-VIII. Sternites II-III with one spine-like setae among three long setae on each side, IV-V with a pair of long setae each side, and VI-VIII with only one long setae on each side. One long pleural seta on III-VIII. Measurements ( $\mathrm{n}=1)$ : HL 0.37, ANW 0.11, POL 0.14, POW 0.27, ADPL 0.12, ADPW 0.14, TRL 0.08, TRW 0.04, TW 0.36, PW 0.21, PTW 0.29, AW 0.43, TL 1.06.

Type specimens. Holotype $\hat{\delta}$ (NHMR \#4322.c) and $1 q$ paratype (NHMR \#4322.b), ex Platysteira cyanea nyansae; UGANDA: Paraa, Murchison Falls, National park, 22.X.1998, P. Becker col.

Non-type specimen. 1 nymph II (NHMR \#4322.b), mounted on the same slide as the female paratype.

\section{Philopteroides pilgrimi Valim \& Palma, sp. n.}

urn:Isid:zoobank.org:act:22B8C261-0710-4C23-85B6-54EA58333235

http://species-id.net/wiki/Philopteroides_pilgrimi

Figs 3-4, 10, 17-20, 32-33

Type host. Gerygone igata igata (Quoy \& Gaimard, 1830) - Grey warbler (Acanthizidae) Distribution. New Zealand. 
Description. Female. Habitus as in Fig. 3 and head as in Fig. 10. Anterior setae 3 (as3) rigid, 0.04-0.05 long, anterior dorsal head setae (ads) minute, 0.02 long. Hyaline membrane with shallow concavity and thin sclerotization; anterior dorsal plate slightly concave and ventral head plate deeply concave (Fig. 32). Pterothorax with 6-8 posteromarginal setae on each side. Tergo-pleural plate II with a reduced postero-lateral projection overlapping segment III, tergo-pleural plate III without projection. Tergocentral setae: II, 5-6 (plus 2 anterior setae); III, 6; IV, 5-6; V, 5-6; VI, 4-6; VII, 5-6; VIII, 5. Tergites VII-IX+X as in Fig. 17. Abdominal sternal setae: segment II, LS-SL; III, LS-SL; IV, SS-SS (rarely LS on one side only); V, SS-SS; VI, LL-LL (one female with one S on one side only). Paratergal setae (all long): II-III, 0; IV-V, 2; VI-VIII, 3. Tergites VIVIII with an innermost seta (included in the paratergal count), lateral to postspiracular seta. Sternites III-VI well-developed as large, rectangular plates. Vulva with 3 medium long setae each side. Subgenital plate, inner genital sclerite, subvulval sclerites, and vulvar margin as in Fig. 18, and intraspecific variation of two additional females as in Figs 18a and 18b. Measurements $(\mathrm{n}=8)$ : HL 0.39-0.43, ANW 0.13-0.15, POL 0.16-0.17, POW 0.28-0.31, ADPL 0.21-0.22, ADPLL 0.14, ADPW 0.13-0.16, TRL 0.09-0.10, TRW 0.03-0.04, TW 0.35-0.41, PW 0.22-0.28, PTL 0.13-0.14, PTW 0.29-0.35, TPVL 0.19-0.25, AW 0.44-0.54, EWG 0.06-0.08; IWG 0.03-0.04, TL 1.35-1.65.

Male. Similar to female, except in dimensions and morphology of terminalia (Figs 4, 19, 20). Pterothorax with 5-6 posteromarginal setae on each side. Tergocentral setae: II, 6 (plus 2 anterior setae); III, 6; IV, 6; V, 6; VI, 6; VII, 6; VIII, 4. Dorsal terminalia as in Fig. 19. Sternal setae as for female. Paratergal setae (all long): II-III, 0; IV-V, 2; VI-VIII, 3. Sternal plates well developed and entire on segments III-VI; subgenital plate with 4 long setae as in Fig. 20, the anterior pair on the plate, and the posterior on the plate margin. Genitalia: length of parameres 0.40 (Fig. 33). Measurements $(\mathrm{n}=1)$ : HL 0.38, ANW 0.14, POL 0.15, POW 0.28, ADPL 0.18, ADPLL 0.13, ADPW 0.14, TRL 0.09, TRW 0.03, TW 0.36, PW 0.21, PTL 0.15, PTW 0.31, TPVL 0.22, AW 0.47, GL 0.19, GW 0.08, TL 1.30.

Type specimens. Holotype $q$ (MONZ AI. 030137), ex Gerygone igata igata; NEW ZEALAND, no other data. Paratypes: 10, 2 ( (MZUSP \#2885), same data as holotype; 2 (MONZ AI.017299), same host species, NEW ZEALAND: Orongorongo Valley, 20.V.1976, B.M. Fitzgerald col.; 1 q (MONZ AI.017301), same host species, NEW ZEALAND: Kowhai Bush, Kaikoura, 15.XI.1976, B. Gill col.; 1 (MONZ AI.017302), same host species, NEW ZEALAND: Orongorongo Valley, 12.V.1977, B.M. Fitzgerald col..

Etymology. This species is named in memory of the late Professor Robert L.C. Pilgrim (1921-2010), for his outstanding contribution to knowledge of ectoparasitic insects, and for his long friendship with RLP (Palma 2011).

Remarks. Morphologically close to $\mathrm{Ph}$. beckeri, especially by features of the head. In addition to the key characters mentioned below, the habitus of both species is distinct (compare Figs 1 and 3; 2 and 4, respectively). Both sexes of Ph. pilgrimi can be distinguished by (1) the presence of spine-like setae on sternite $\mathrm{V}$ (absent in Ph. beckeri); (2) female tergites IX+X with long innermost setae situated on the tergal plate (Fig. 17) (on soft tegument in Ph. beckeri, Fig. 13); (3) female subgenital plate without 
medial setae (Fig. 18) (against three pairs of setae on each side, as in Ph. beckeri, Fig. 14); (4) shape of sub-vulval sclerites (compare Figs 14 and 18); (5) male subgenital plates (compare Figs 16 and 20); and (6) male genitalia (compare Figs 31 and 33).

\section{mitsusui species-group}

The approximately triangular shape of the head is the distinctive character in the ten species included in this group. The preantennal region is longer (POL 0.22-0.29) and narrower (ANW 0.10-0.12) than in the beckeri species-group, and the hyaline margin is deeply concave at midline. Conus well-developed.

\section{Philopteroides mitsusui (Uchida, 1948)}

Bitrabeculus mitsusui Uchida, 1948: 321, fig. 7.

Philopterus mitsusui (Uchida, 1948); Hopkins and Clay 1952: 286; Price et al. 2003: 215. Philopteroides mitsusui (Uchida, 1948); Mey 2004: 174.

Type host. Myzomela rubratra dichromata Wetmore, 1919 - Micronesian honeyeater (Meliphagidae)

Distribution. Pohnpei I., Caroline Islands, Micronesia.

\section{Philopteroides kayanobori (Uchida, 1948)}

Bitrabeculus kayanobori Uchida, 1948: 322, fig. 8.

Philopterus kayanobori (Uchida, 1948); Hopkins and Clay 1952: 285; Price et al. 2003: 214.

Philopteroides kayanobori (Uchida, 1948); Mey 2004: 174.

Type host. Spizixos semitorques cinereicapillus Swinhoe, 1871 - Collared finchbill bulbul (Pycnonotidae)

Distribution. Taiwan.

\section{Philopteroides sclerotifrons (Tandan, 1955)}

Philopterus sclerotifrons Tandan, 1955: 417, figs 1-7. Price et al. 2003: 216. Philopteroides sclerotifrons (Tandan, 1955); Mey 2004: 174.

Type host. Cinnyris asiaticus asiaticus (Latham, 1790) - Purple sunbird (Nectariniidae) Distribution. India. 
Philopteroides novaezelandiae Mey, 2004

Philopteroides novaezelandiae Mey, 2004: 174, figs 21-22c,d.

Type host. Acanthisitta chloris chloris (Sparrman, 1787) - Rifleman (Acanthisittidae)

Distribution. South Island, New Zealand.

Philopteroides xenicus Mey, 2004

Philopteroides xenicus Mey, 2004: 176, fig. 22a,b,e.

Type host: Xenicus longipes longipes (Gmelin, 1789) - Bush wren (Acanthisittidae)

Distribution. South Island, New Zealand.

Philopteroides cucphuongensis Mey, 2004

Philopteroides cucphuongensis Mey, 2004: 176, fig. 23, table 2.

Type host: Pycnonotus finlaysoni eous Riley, 1940 - Stripe-throated bulbul (Pycnonotidae)

Distribution. Vietnam.

Philopteroides flavala Najer and Sychra, 2012

Philopteroides flavala Najer and Sychra, 2012a: 39, figs 1, 2A-G, 5A-B.

Type host: Hemixos flavala Blyth, 1845 - Ashy bulbul (Pycnonotidae)

Distribution. Vietnam.

Philopteroides terpsiphoni Najer and Sychra, 2012

Philopteroides terpsiphoni Najer and Sychra, 2012b: 95, figs 6-12.

Type host: Terpsiphone viridis (Statius Müller, 1776) - African paradise-flyctacher (Monarchidae)

Distribution. Senegal. 


\section{Philopteroides fuliginosus Valim \& Palma, sp. n.}

urn:lsid:zoobank.org:act:70A9F313-D518-4143-A683-E76F8168787B

http://species-id.net/wiki/Philopteroides_fuliginosus

Figs 5-6, 11, 21-24, 34-35

Type host. Rhipidura fuliginosa placabilis Bangs, 1921 - New Zealand fantail (Rhipiduridae)

Distribution. New Zealand.

Description. Female. Habitus as in Fig. 5 and head as in Fig. 11. Anterior setae 3 (as3) rigid, 0.04-0.05 long; anterior dorsal head setae (ads) peg-like, 0.02 long. Hyaline membrane with deep concavity and thick sclerotization of its margin, 0.03-0.04 long; anterior margin of the anterior dorsal plate deeply concave and ventral head plate more concave than the dorsal one (Fig.34). Pterothorax with 8 posteromarginal setae on each side. Tergo-pleural plate II with a reduced postero-lateral projection overlapping segment III, tergo-pleural plate III without any projection. Tergocentral setae: II, 12-13 (plus 2 anterior setae); III, 15-16; IV, 13-18; V, 16-19; VI, 16-17; VII, 12-14; VIII, 6-12. Tergites VII-IX+X as in Fig. 21. Sternal setae (intraspecific variation in parentheses): II, SL-SL (plus 1-2 long setae laterad to sternal plate); III, LL-SLL (LSL-SLL); IV, LLSLL-LLSLL (LLSLL-LSLLL); V, LLSLL-LLSLL (LLSLLLSLLL); VI, LLLL-LLLL (LLLLL-LLLL). Segments IV-VII with 1-4 long additional setae situated on soft tegument, between the sternal plate and the pleural setae. Paratergal setae (all long): II-III, 0; IV-V, 3; VI, 4 (rarely 3 on one side only); VII, 3-4; VIII, 1-2. Segments VI-VIII with an innermost dorsal seta on each tergite (included in the paratergal count), besides the postspiracular seta. Sternites III-VI with welldeveloped, large plates, roughly rectangular. Vulva with 7-9 medium long setae each side, and 4-6 small setae on the middle of the vulvar margin. Subgenital plate, inner genital sclerite, subvulval sclerites, and vulvar margin as in Fig. 22. Measurements (n $=8$ ): HL 0.45-0.48, ANW 0.09-0.10, POL 0.20-0.22, POW 0.31-0.32, ADPL 0.18-0.20, ADPLL 0.15-0.16, ADPW 0.13-0.14, TRL 0.09-0.10, TRW 0.03-0.04, TW 0.43-0.46, PW 0.25-0.26, PTL 0.16-0.18, PTW 0.35-0.37, TPVL 0.21-0.23, AW 0.53-0.60, EWG 0.05-0.06; IWG 0.03-0.04, TL 1.37-1.49.

Male. Similar to female, except in dimensions and morphology of terminalia (Fig. 6). Pterothorax with 7-9 posteromarginal setae on each side. Tergocentral setae: II, 11-14 (plus 2 anterior setae); III, 10-18; IV, 10-17; V, 9-19; VI, 10-18; VII, 11-13; VIII, 7-8. Tergites VII-IX+X as in Fig. 23. Paratergal setae (all long): II-III, 0; IV-V, 2-4; VI-VII, 3-4; VIII, 2. Sternal plates well developed and entire on segments III-VI; subgenital plate with 4 proximal long setae and 2 distal postero-lateral long setae (Fig. 24). Genitalia: length of parameres 0.50 (Fig. 35). Measurements (n $=8$ ): HL 0.42-0.46, ANW 0.09-0.10, POL 0.20-0.21, POW 0.28-0.30, ADPL 0.18-0.19, ADPLL 0.14-0.15, ADPW 0.11-0.12, TRL 0.09-0.10, TRW 0.03-0.05, TW 0.40-0.42, PW 0.24-0.25, PTL 0.14-0.16, PTW 0.32-0.35, TPVL 0.20-0.21, AW 0.47-0.53, GL 0.21-0.23, GW 0.06-0.07, TL 1.12-1.24. 


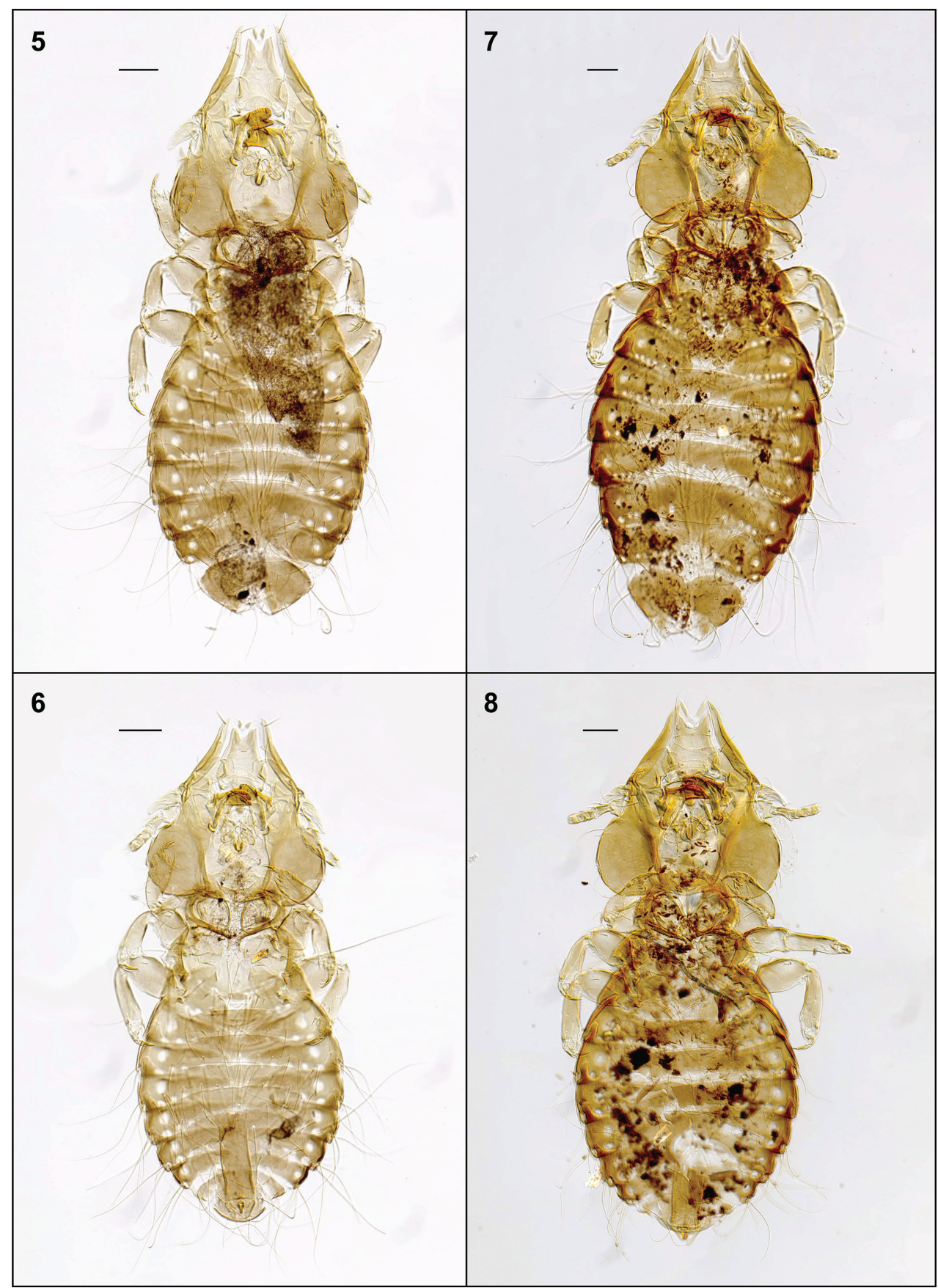

Figures 5-8. Habitus, ventral views: Philopteroides fuliginosus female holotype (5); Ph. fuliginosus male paratype (6); Ph. macrocephalus female holotype (7); Ph. macrocephalus male paratype (8). Scale bars $=0.1 \mathrm{~mm}$ 
Type specimens. Holotype $q$ (MONZ AI. 030138), ex Rhipidura fuliginosa placabilis, NEW ZEALAND: Otaihanga, Paraparaumu, WN, 23.III.1996, N. Hyde col. Paratypes: $2 \hat{\jmath}$ (MONZ AI.017297), 10, $1 \uparrow$ (MZUSP \#2886), same data as holo-

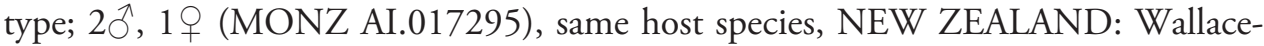
ville Animal Research Centre, Upper Hutt, 4.IV.1974, D.M. Pearce col.; $1{ }^{\Uparrow}$ (MONZ AI.017296), same host species, NEW ZEALAND: Little Barrier I., 1.IX.1977, C.R. Veitch col.; $1{ }^{\widehat{T}}$ (MONZ AI.017298), same host species, NEW ZEALAND: Days Bay, Wellington, 8.II.2003, E.W. Dawson col.

Additional specimens, non-types. $1 \sigma^{\hat{}}$ (MONZ AI.017290), ex Rhipidura fuliginosa fuliginosa (Sparrman, 1787), NEW ZEALAND: Jackson Bay, Westland, 6.VII.1969, W. Spiekman col.; 19 (MONZ AI.017291), NEW ZEALAND: Coutts I., Canterbury, 22.XII.1970, J.R. Jackson col.; 10, 1 ㅇ (MONZ AI.017292), NEW ZEALAND: Nelson, 8.V.1972, B.A. Holloway col.; 2へ, 2 ( $(M O N Z$ AI.017293), NEW ZEALAND: Nelson, 22.V.1972, G. Kuschel col.; 1 ㅇ (MONZ AI.017294), NEW ZEALAND: Franz Joseph Glacier, 1973-1974, P. Fletcher col.

Etymology. The species epithet is a noun in apposition derived from the species name of the host, and also refers to the dark colour of the lice.

Remarks. Morphologically close to $P h$. macrocephalus by having: anterior dorsal head setae (ads) peg-like; segment III without pleural setae; segment IV with 2 pleural setae; sternite VI without spine-like setae; setae of the male subgenital plate situated on the plate. However, both sexes of $P h$. fuliginosus can be distinguished from those of $P$. macrocephalus by: (1) the hyaline margin with a shallower indentation $(0.03-0.04 \mathrm{~mm})$ at its midline (compare Figs 11 and 12; 34 and 36); (2) the female tergal chaetotaxy and shape of tergites IX+X (Fig. 21); (3) the male subgenital plate (Fig. 24); and (4) the male genitalia (Fig. 34).

\section{Philopteroides macrocephalus Valim \& Palma, sp. n.}

urn:lsid:zoobank.org:act:968250A7-D7C5-470A-8BFE-5EBA96AC5314

http://species-id.net/wiki/Philopteroides_macrocephalus

Figs $7-8,12,25-28,36-37$

Type host. Petroica macrocephala macrocephala (Gmelin, 1789) - New Zealand tit or tomtit (Petroicidae)

Distribution. New Zealand.

Description. Female. Habitus as in Fig. 7, and head as in Fig. 12. Anterior setae 3 (as3) rigid, peg-shaped, 0.05-0.06 long; anterior dorsal head setae (ads) peg-like, 0.02 long. Hyaline membrane with deep concavity and thin sclerotization, $0.06-0.08$ long; anterior dorsal plate slightly concave and ventral head plate deeply concave (Fig. 36). Pterothorax with 9 posteromarginal setae on each side. Tergo-pleural plate II with a much reduced posterolateral projection overlapping segment III; tergo-pleural plate III without any projection. Tergocentral setae: II, 17-19 (plus 2 anterior setae); III, 23-25; IV, 25-27; V, 26-27; VI, 24-26; VII, 23-25; VIII, 12-14. Tergites VII-IX+X as in Fig. 25. Sternal setae: II, SL-LS; III, LLLLSL-LSLLLL; IV, LLLLSLL-LLSLLLL; V, LLLLLSLL-LLSLLLLL; VI, LLLLL- 


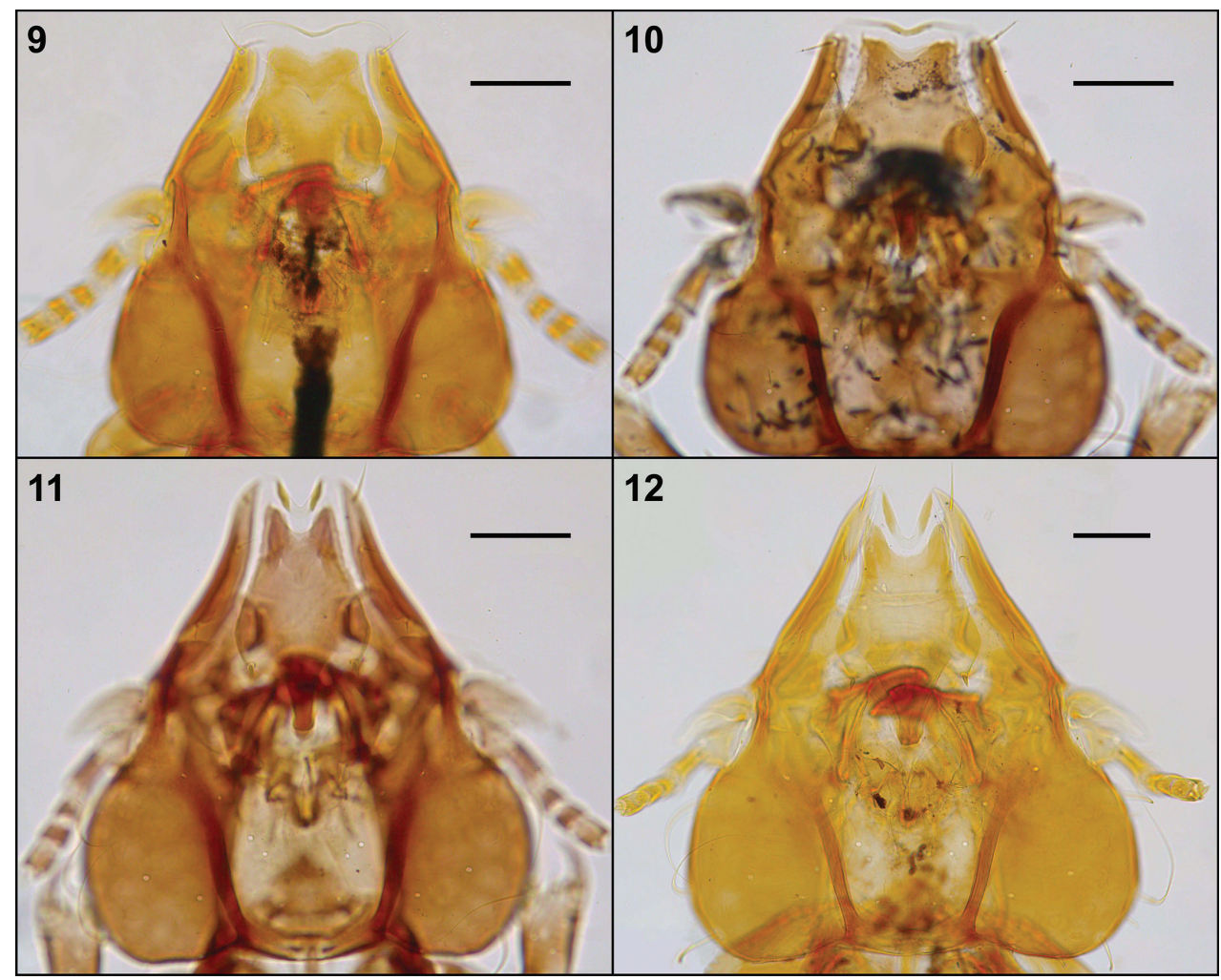

Figures 9-12. Head, dorsal view: Philopteroides beckeri female paratype (9); Ph. pilgrimi female holotype (I 0); Ph. fuliginosus female (I I); Ph. macrocephalus female holotype (I 2). Scale bars $=0.1 \mathrm{~mm}$

LLLLL (some specimens show slight variations from this symmetrical pattern). Segments II-VII with 3-5 additional long setae situated on the soft tegument, between the sternal plate and the pleural setae. Paratergal setae (all long): II-III, 0; IV, 5-6; V, 4-5; VI-VII, 4; VIII, 2. Tergites VI-VII with an innermost dorsal seta (included in the paratergal count), besides the postspiracular setae (not included in the count). Sternites III-VI with large, welldeveloped plates, roughly rectangular. Vulva with 9-11 medium to long setae each side, and 14-15 small setae in the middle of the vulvar margin. Subgenital plate, inner genital sclerite, subvulval sclerites, and vulvar margin as in Fig. 26, plus a variation of an additional female in Fig. 26a. Measurements $(\mathrm{n}=7)$ : HL 0.59-0.62, ANW 0.10-0.12, POL 0.28-0.30, POW 0.40-0.41, ADPL 0.24-0.25, ADPLL 0.20-0.21, ADPW 0.18-0.19, TRL 0.110.13, TRW 0.04-0.05, TW 0.58-0.64, PW 0.30-0.36, PTL 0.21-0.25, PTW 0.44-0.48, TPVL 0.25-0.27, AW 0.72-0.79, EWG 0.05-0.06, IWG 0.03-0.04, TL 1.85-2.13.

Male. Similar to female, except in dimensions and morphology of terminalia (Fig. 8). Pterothorax with 7-9 posteromarginal setae on each side. Tergocentral setae: II, 17-18 (plus 2 anterior setae); III, 17-19; IV, 22-24; V, 18-20; VI, 17-20; VII, 16-18; VIII, 10-12. Paratergal setae (all long): II-III, 0; IV-V, 4 (rarely 2 setae on one side only); VI-VII, 4-5 (rarely 3 setae on one side only); VIII, 2. Sternal plates III-VI well 


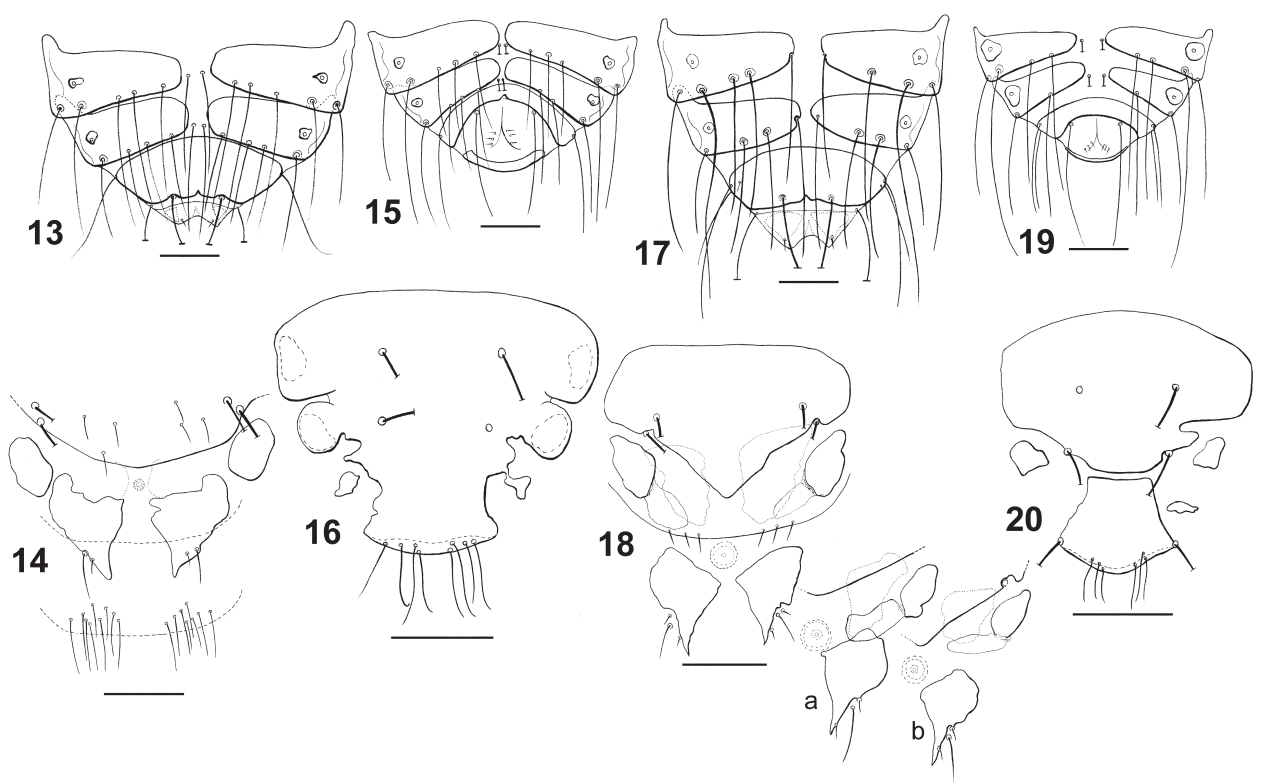

Figures 13-20. Dorsal terminalia: Philopteroides beckeri female (13); Ph. beckeri male (15); Ph. pilgrimi female (I7); Ph. pilgrimi male (19). Female ventral terminalia: Ph. beckeri (14); Ph. pilgrimi (I8); Ph. pilgrimi intraspecific variation (I 8a,b). Male subgenital plate: Ph. beckeri (I6); Ph. pilgrimi (20). Scale bars $=0.1 \mathrm{~mm}$.

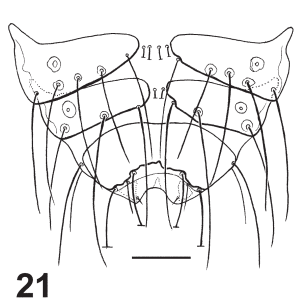

21

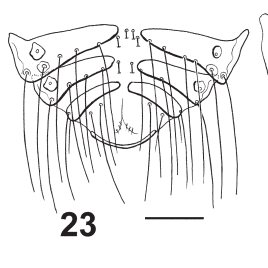

23

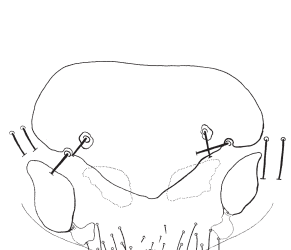

22

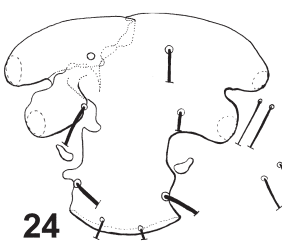

\section{6}

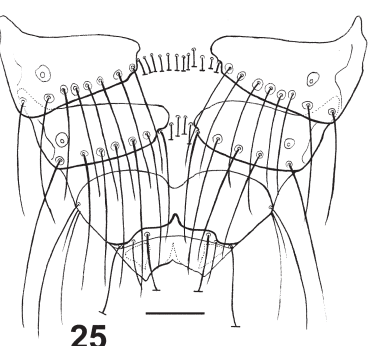

25

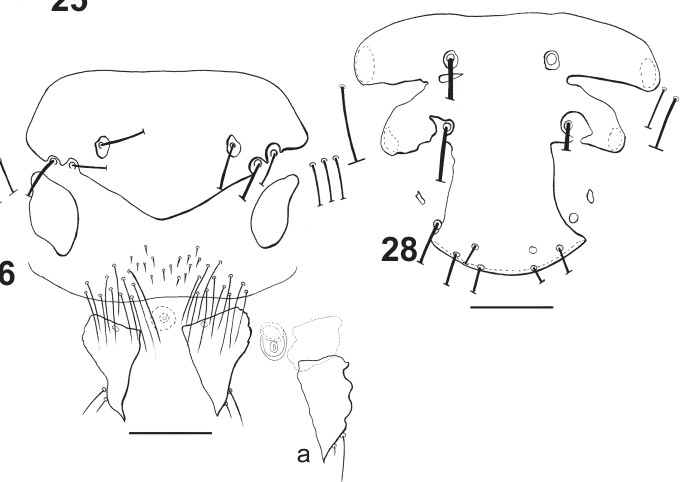

Figures 2I-28. Dorsal terminalia: Philopteroides fuliginosus female (2I); Ph. fuliginosus male (23); Ph. macrocephalus female (25); Ph. macrocephalus male (27). Female ventral terminalia: Ph. fuliginosus (22); Ph. macrocephalus (26); Ph. macrocephalus intraspecific variation (26a). Male subgenital plate: Ph. fuliginosus (24); Ph. macrocephalus (28). Scale bars $=0.1 \mathrm{~mm}$. 


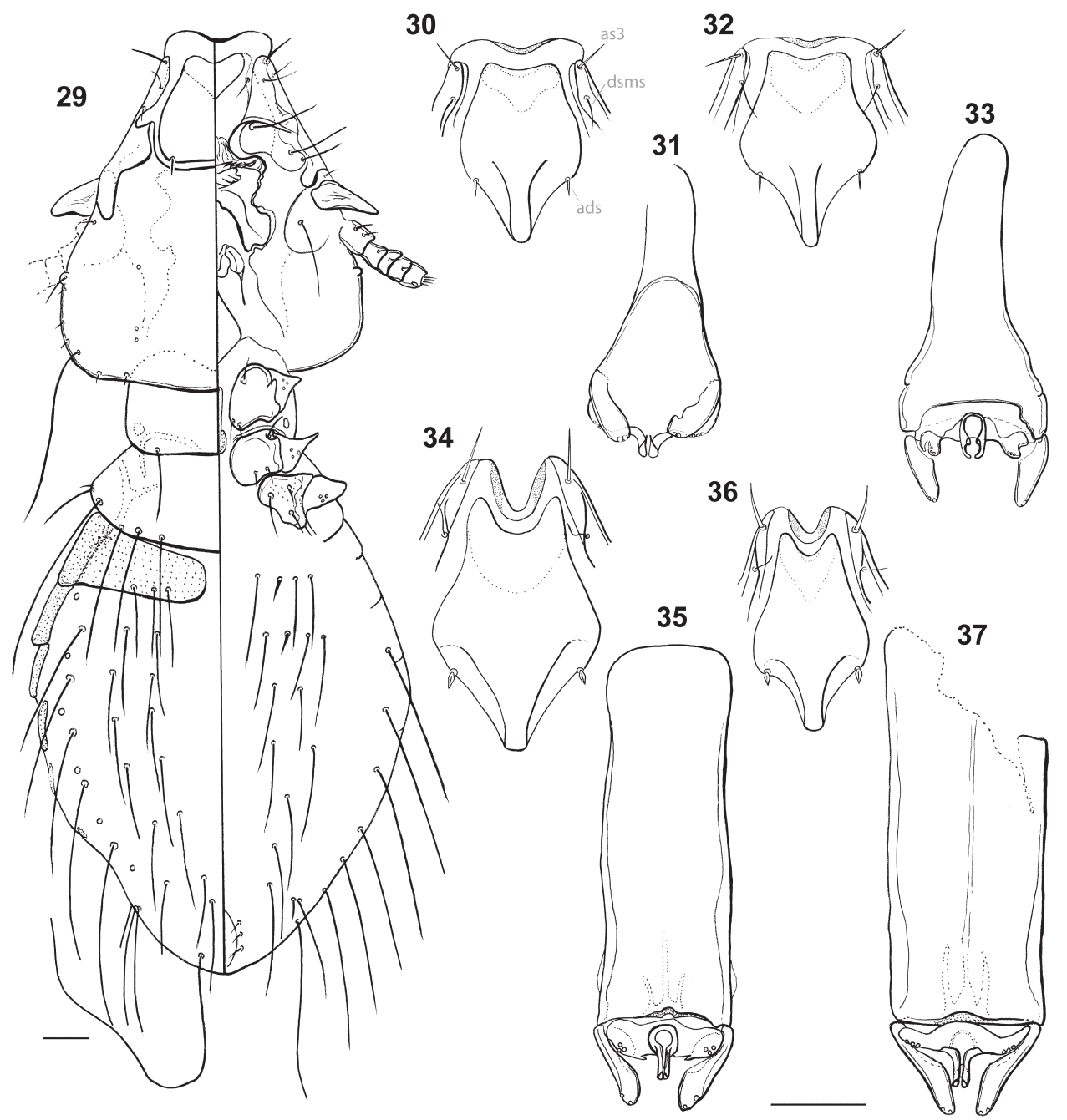

Figures 29-37. Habitus: Philopteroides beckeri nymph II, dorso-ventral view (29). Hyaline margins and anterior dorsal plates: Ph. beckeri (30); Ph. pilgrimi (32); Ph. fuliginosus (34); Ph. macrocephalus (36). Male genitalia: Ph. beckeri (3I); Ph. pilgrimi (33); Ph. fuliginosus (35); Ph. macrocephalus (37). Scale bars $=0.05 \mathrm{~mm}$

developed and entire; 4 long setae on the subgenital plate with only the anterior pair situated on the plate (Fig. 28). Genitalia: length of parameres 0.50 (Fig. 37). Measurements $(\mathrm{n}=9)$ : HL 0.55-0.57, ANW 0.10-0.12, POL 0.27-0.28, POW 0.37-0.39, ADPL 0.23-0.25, ADPLL 0.27-0.28, ADPW 0.16-0.17, TRL 0.10-0.12, TRW 0.04-0.05, TW 0.51-0.55, PW 0.28-0.30, PTL 0.17-0.20, PTW 0.42-0.44, TPVL 0.25-26, AW 0.62-0.65, GL 0.27-0.32, GW 0.07-0.08, TL 1.49-1.61.

Type specimens. Holotype + (MONZ AI.030122), ex Petroica macrocephala macrocephala, NEW ZEALAND: Haast Pass, 30.IX.1969, C.N. Challies col. (University of Canterbury). Paratypes: $3 \hat{\delta}, 3 q$ (MONZ AI.017278 \& AI.017279), $1 \hat{\jmath}, 1$ 우 (MZUSP \#2887), same data as holotype. 
Additional specimens, non-types. 2 (MONZ AI.017281), ex Petroica macrocephala dannefaerdi (Rothschild, 1894), NEW ZEALAND: Penguin Creek, Snares Island, 29.III.1972, D.S. Horning \& C.J. Horning cols.; 10 (MONZ AI.017282), NEW ZEALAND: Boat Harbour, Snares Is, 22.II.1975, H.A. Best col.; $1 \overbrace{}^{\jmath}$ (MONZ AI.017283), NEW ZEALAND: Station Point, Snares Island, 25.II.1977, D.S. Horning col.; $1 \overbrace{}^{\Uparrow}$ (MONZ AI.017284), NEW ZEALAND: Tern Point, Snares Islands, 10.I.1987, A. Tennyson col.; $1{ }^{\Uparrow}$ (MONZ AI.017280), NEW ZEALAND: Snares Is, no date, CMu Av. 4635. 1ठ̄ (MONZ AI.017277), ex Petroica macrocephala, NEW ZEALAND: Springs Junction, Maruia, 20.VIII.1966, J.R. Jackson col.

Etymology. The species epithet is a noun in apposition derived from the species name of the host, and also refers to the larger head of this louse species.

Remarks. Morphologically close to Ph. fuliginosus by the features mentioned under that species above. However, both sexes of $\mathrm{Ph}$. macrocephalus can be distinguished from those of Ph. fuliginosus by (1) the hyaline margin with a deeper incision $(0.06-0.08 \mathrm{~mm})$ at its midline (compare Figs 11 and 12, Figs 34 and 36); (2) the female tergal chaetotaxy and shape of tergites IX+X (compare Figs 21 and 25); (3) the male subgenital plate (compare Figs 24 and 28); and (4) the male genitalia (compare Figs 35 and 37).

\section{Key to the species of Philopteroides Mey, 2004 (adults only)*}

\section{*except Philopteroides lineatus (Giebel, 1874)}

1 Preantennal region short (POL $\leq 0.15-0.17)$ and broad (ANW $\geq 0.13-0.15)$; hyaline margin with a shallow concavity at midline (Figs 9-10, 30, 32) ....... beckeri species-group...2

- $\quad$ Preantennal region long (POL $\geq 0.20-0.28)$ and narrow (ANW $\leq 0.10-0.12$ ); hyaline margin with a deep concavity at midline (Figs 11-12, 34, 36)

mitsusui species-group...3

Sternite V without spine-like setae. Females: posterior setae on tergite IX+X situated outside plate (Fig. 13); subgenital plate with median setae (Fig. 14)

Ph. beckeri (Mey, 2004)

Sternite $\mathrm{V}$ with at least one pair of spine-like setae. Females: posterior setae on tergite IX+X situated on plate (Fig. 17); subgenital plate without median setae (Fig. 18) Ph. pilgrimi Valim \& Palma, sp. n. Pleural setae present on segment III Ph. kayanobori (Uchida, 1948) Pleural setae absent on segment II. Pleural segment IV with only 1 setae on each side... Ph. mitsusui (Uchida, 1948) Pleural segment IV with 2 or more setae on each side ............................5 Anterior dorsal setae (ads) peg-like (Figs 34, 36) Sternite VI with at least one pair of spine-like setae; without additional setae between pleural and sternal setae; sternites sexually dimorphic. 
- $\quad$ Sternite VI without spine-like setae; with additional setae between pleural and sternal setae, situated on soft tegument; sternites not dimorphic .........7 7

$7 \quad$ Males: anterior setae of the subgenital plate situated outside plate .............8

- Males: anterior setae of the subgenital plate situated on plate ....................9

8 Sternite $\mathrm{V}$ with at least one pair of spine-like setae. Male genitalia with a large trapezoidal medial sclerite on basal plate (as in fig. 22e in Mey 2004: 175)...

Ph. xenicus Mey, 2004

- $\quad$ Sternite V without spine-like setae. Male genitalia with a small roughly oval medial sclerite on basal plate (as in fig. 22d in Mey 2004: 175)

Ph. novaezelandiae Mey, 2004

9 Hyaline margin with a deep incision $(0.06-0.08 \mathrm{~mm})$ at its midline (Figs 12 , 36). Female tergite IX $+X$ with an anterior and a posterior notch (Fig. 25). Lateral margin of the male subgenital plate with deep incisions (Fig. 28); male genitalia as in Fig. 37....... Ph. macrocephalus Valim \& Palma, sp. n.

- Hyaline margin with a shallow incision $(0.03-0.04 \mathrm{~mm})$ at its midline (Figs 11, 34). Female tergite IX+X without anterior notch and with an uneven posterior margin (Fig. 21). Lateral margin of the male subgenital plate with shallow incisions (Fig. 24); male genitalia as in Fig. 35

Ph. fuliginosus Valim \& Palma, sp. n.

10 Females without central sternal plates, only with lateral rounded sternal plates on III-VI. Males without lateral rounded sternal plates

Ph. sclerotifrons (Tandan, 1955)

- $\quad$ Females with central sternal plates, including lateral rounded sternal plates on III-VI (occasionally fused with the central plates). Males with lateral rounded sternites on at least segment III

11 With lateral rounded sternal plates on segment II. Females with a central sclerite plus two rounded lateral ones (separated from each other) on sternite VI

Ph. flavala Najer \& Sychra, 2012

- Without lateral sternal plates on segment II. Females with a unique central sclerite, and only vestiges of lateral rounded sternites (fused to the central sclerite) on sternite VI

Ph. cucphuongensis Mey, 2004

\section{Acknowledgements}

We thank Dr Eberhard Mey (Naturhistorischen Museum, Rudolstadt, Thüringen, Germany) for the loan of the types of Tyranniphilopterus beckeri deposited in NHMR, and for his assistance in the interpretation of the original German description of Docophorus lineatus in Giebel (1874). This study was partially supported by the FAPESP - São Paulo Research Foundation (MPV: 2011/11420-5; 2012/06951-4). We thank two anonymous referees for useful comments that improved our original manuscript. 


\section{References}

Cicchino AC (2007) Tyranniphilopterus polioptilus new species (Phthiraptera: Ischnocera: Philopteridae) parasitic on the masked gnatcatcher, Polioptila dumicola (Passeriformes, Polioptilidae) in Argentina. Zootaxa 1547: 43-50.

Clay T (1951) An introduction to a classification of the avian Ischnocera (Mallophaga): Part I. The transactions of the Royal Entomological Society of London 102 (2): 171-194.

Dickinson EC (Ed) (2003) The Howard \& Moore complete checklist of the birds of the world (Third edition). Christopher Helm, London. 1040 pp.

Giebel CGA (1874) Insecta epizoa. Die auf Säugetieren und Vögeln schmarotzenden Insecten nach Chr. L. Nitzsch's Nachlass bearbeitet. O. Wiegand, Leipzig. xvi + 308 pp., pls 1-20.

Harrison L (1916) The genera and species of Mallophaga. Parasitology 9(1): 1-156. doi: $10.1017 /$ S0031182000005989

Hopkins GHE, Clay T (1952) A check list of the genera \& species of Mallophaga. Trustees of the British Museum, London. 362 pp.

Mey E (1994) Beziehungen zwischen Larvenmorphologie und Systematik der Adulti bei den Vogel-Ischnozeren (Insecta, Phthiraptera, Ischnocera). Mitteilungen aus dem Zoologischen Museum in Berlin 70(1): 3-84. doi: 10.1002/mmnz.19940700102

Mey E (2004) Zur Taxonomie, Verbreitung und parasitophyletischer Evidenz des PhilopterusKomplexes (Insecta, Phthiraptera, Ischnocera). Ornithologischer Anzeiger 43(2): 149-203.

Najer T, Sychra O, Hung NM, Čapek M, Podzemny P, Literák I (2012a) New species and new records of chewing lice (Phthiraptera: Amblycera and Ischnocera) from bulbuls (Passeriformes: Pycnonotidae) in Vietnam. Zootaxa 3357: 37-48.

Najer T, Sychra O, Literák I, Procházka P, Čapek M, Koubek P (2012b) Chewing lice (Phthiraptera) from wild birds in Senegal, with descriptions of three new species of the genera Brueelia and Philopteroides. Acta Parasitologica 57(1): 90-98. doi: 10.2478/s11686-012-0005-x

Palma RL (1978) Slide-mounting of lice: a detailed description of the Canada balsam technique. New Zealand entomologist 6(4): 432-436. doi: 10.1080/00779962.1978.9722313

Palma RL (2011) A tribute to Robert Louis Cecil Pilgrim. Research Associate, Museum of New Zealand Te Papa Tongarewa. Tuhinga - Records of the Museum of New Zealand Te Papa Tongarewa 22: 149-156.

Price RD, Hellenthal RA, Palma RL (2003) World checklist of chewing lice with host associations and keys to families and genera. In: Price RD, Hellenthal RA, Palma RL, Johnson $\mathrm{KP}$, Clayton DH (Ed) The chewing lice. World checklist and biological overview. Illinois Natural History Survey Special Publication 24, 1-448.

Tandan BK (1955) Mallophagan parasites from Indian birds. Part IV. Species belonging to the genera Philopterus, Capraiella and Pectinopygus (superfamily Ischnocera). Annals and magazine of natural history (Series 12) 8: 417-433.

Uchida S (1948) Studies on the biting-lice (Mallophaga) of Japan and adjacent territories (suborder Ischnocera Pt. I). The Japanese Medical Journal 1(4): 303-326. 